\title{
OPTIMIZATION OF CLINICAL DIAGNOSIS AND TREATMENT OF ACUTE TONSILLOPHARYNGITIS IN CHILDREN
}

\author{
Olena K. KOLOSKOVA ${ }^{1}$, Leonid O. BEZRUKOV ${ }^{1}$, Loryna A. IVANOVA ${ }^{1}$, Inna B. HORBATIUK ${ }^{1}$, \\ Iryna B. HORBATIUK ${ }^{2}$ \\ ${ }^{1}$ Department of Pediatrics and Children Infectious Diseases of Bukovinian State Medical University, \\ Chernivtsi, Ukraine \\ ${ }^{2}$ Department of Internal Medicine, Clinical Pharmacology and Occupational Disease of Bukovinian State \\ Medical University, Chernivtsi, Ukraine
}

Received 28 Sept 2018, Corrections received 27 Jan 2019, Accepted 30 Jan 2019

https://doi.org/10.31688/ABMU.2019.54.1.07

\begin{abstract}
Introduction. Administration of antibiotics in case of acute tonsillopharyngitis (ATP) is reasonable only when the disease is caused by $\beta$-hemolytic streptococcus of A (BHSA) group, although clinical confirmation of its etiology is rather complicated.

Objective. Improvement of the diagnosis and treatment of acute tonsillopharyngitis in children, considering the etiological factor and the clinical characteristics of the course of this disease.

Materials and methods. 102 children with acute tonsillopharyngitis were included in the study. The patients were divided in 2 groups. The first group included 68 patients with non-streptococcal acute tonsillopharyngitis (nATP), the second one - 34 children with streptococcal acute tonsillopharyngitis (sATP) with BHSA. The study was performed in the Children Regional Hospital, Chernivtsi, Ukraine, during the period 2014-2016. General clinical examination was performed in all the children, using MacIsaac, Centor and Breeze probabilistic-orientation clinical systems.
\end{abstract}

\section{RÉsumé}

Loptimisation du diagnostic clinique et du traitement de la pharyngo-tonsillite aiguë chez les enfants

Introduction. La prise d'antibiotiques dans les cas d'une amygdalite aiguë ne se justifie que dans le cas de la maladie causée par le streptocoque $\beta$-hémolytique du groupe A. Cependant, la vérification clinique de l'étiologie est plutôt difficile.

L'objectif de la recherche. L'amélioration du diagnostic clinique et du traitement de l'amygdalite aiguë chez les enfants.

Matériaux et méthodes. 102 enfants présentant une amygdalo-pharyngite aiguë ont été impliqués dans l'étude. Les patients ont été divisés en 2 groupes. Le premier groupe comprenait 68 patients présentant une amygdalo-pharyngite aiguë non streptococcique (NATP), le second - 34 enfants atteints de BHSA (sATP). L'étude a été réalisée dans la clinique de l'hôpital régional pour enfants, dans la ville de Tchernivtsi, en Ukraïne, pour la période 2014-2016. À l'hôpital, 
Constellation pattern of ATP was simulated by successive Waald's method in Kulbak's modification.

Results. MacIsaac and Centor clinical systems, with the total sum less than 3, with a specificity of $93.9 \%$ and a sensitivity of $12.5 \%$, were indicative of non-streptococcal acute tonsillitis in children. The prospective 1-year observation of children who had ATP determined that every third child from the $1^{\text {st }}$ group and half of the representatives from the $2^{\text {nd }}$ group presented different complaints associated with vegetative-vascular dystonia syndrome. In case of impossible microbiological examination in patients with ATP, we have suggested the algorithm of a rational administration of antibiotics for its treatment.

Conclusions. MacIsaac and Centor probabilistic-orientation clinical systems with the total sum of less than 3 are indicative of non-streptococcal acute tonsillitis in children, with a high specificity, but low sensitivity. Therefore, according to our research, to reduce the risk of insufficient diagnosis of acute tonsillopharyngitis caused by $\beta$-hemolytic streptococcus when microbiological examination is not possible, a multilevel algorithm for its treatment should be used.

Keywords: children, acute non-streptococcal, streptococcal tonsillopharyngitis.

\section{Abbreviations:}

ATP - acute tonsillopharyngitis

sATP-streptococcal acute tonsillopharyngitis

nATP - non-streptococcal acute tonsillopharyngitis

BHSA - $\beta$-hemolytic streptococcus of A group

VVD - vegetative-vascular dystonia

\section{INTRODUCTION}

Considering the self-limiting character of acute tonsillopharyngitis (ATP) in immune competent children, administration of antibiotics is reasonable only if the disease is caused by $\beta$-hemolytic streptococcus of A group (BHSA), to reduce the risk of development of purulent and immune-mediated complications ${ }^{1-5}$. At the same time, it should be noted that ATP diagnosis caused by BHSA, on the basis of clinical manifestations, appears to be ineffective, due to the absence of reliable differences to non-streptococcal infections $s^{6.8}$. Microbiological methods of examination are necessary in order to confirm or exclude the BHSA-etiology of ATP, which is usually not available for general practitioners. Moreover, even microbiological examinations and methods of antigen quick detection do not have absolute diagnostic value $^{9-12}$. Finally, it results in an irrationally wide tous les enfants ont ont été soumis à un essai clinique général utilisant McAzake, Tsentor et Briz. Le modèle de constellation de l'ATP a été créé en utilisant la méthode séquentielle de Waals dans la modification de Kulbak.

Résultats et discussion. Les systèmes cliniques MacIsaac et Centor avec une somme totale inférieure à 3, avec une spécificité de 93,9\%, une sensibilité de $12,5 \%$, étaient une indication d'une amygdalite aiguë non streptococcique chez l'enfant. Dans l'observation prospective pour un an des enfants atteints de ATP, il a été noté que chaque enfant sur trois du groupe I et la moitié des représentants du groupe II présentaient divers troubles associés au syndrome de dystonie végétative-vasculaire. En cas de l'impossibilité d'un examen microbiologique chez les patients atteints d'ATP, nous avons proposé l'algorithme d'une administration rationnelle d'antibiotiques pour son traitement.

Conclusion. Les systèmes cliniques d'orientation probables MacIsaac et Centor avec une somme totale inférieure à 3 indiquent une amygdalite aiguë non streptococcique chez les enfants avec une spécificité élevée, mais une faible sensibilité. Par conséquent, selon la recherche de données, pour réduire le risque de diagnostics insuffisants de l'amygdalite aiguë causée par le streptocoque $\beta$-hémolytique lorsque l'examen microbiologique culturel n'est pas possible, l'algorithme à multiniveaux de son traitement doit être utilisé.

Mots-clés: enfants, amygdalite aiguë nonstreptococcique, amygdalite aiguë streptococcique.

administration of antibiotics, with increased incidence of their side effects.

The objective OF THE STUdY was to improve the clinical diagnosis and treatment of acute tonsillopharyngitis in children, considering the etiological factor and clinical characteristics of the course of this disease.

\section{Materials AND MEthods}

For this purpose, 102 children, who have been hospitalized with ATP, were examined in the Infectious Department of the Children Regional Hospital of Chernivtsi, Ukraine, during the period 2014-2016. Depending on the presence or absence of BHSA in the inoculation taken from the tonsillar surface, the patients were divided into two groups. The first group included 68 patients with non-streptococcal ATP (nATP), and the second group - 34 children 
with BHSA identified in bacterial inoculation (sATP). The average age of children from the first group was 9.2 years, and in the $2^{\text {nd }}$ group 7.5 years $(\mathrm{p}>0.05)$. There were $52.2 \%$ boys and $38.2 \%$ girls.

The results of the study were analysed with biostatistical and clinical epidemiological methods. Parametric methods of the analysis were applied in case of normal distribution with evaluation of differences by Student t-criterion. The data were processed by the program STATISTICA 7,0. To establish the diagnostic value, their sensitivity, specificity, predicted positive and negative values were determined. Attributive and relative risks were assessed, odds ratio and confidence intervals (95\% CI) were calculated.

Children of the $1^{\text {st }}$ group were admitted in the $2.8 \pm 0.17$ days since the onset of the disease, while the representatives of the $2^{\text {nd }}$ group in the $3.8 \pm 0.66$ days $(p>0.05)$. Every fourth child, regardless of the etiological factor of acute tonsillopharyngitis, received antibacterial drugs of $\beta$-lactam group, as out-patient. In the hospital, all the children were examined according to MacIsaac, Centor and Breeze probabilistic-orientation clinical systems $\mathrm{s}^{13-17}$. Expression of the clinical symptoms of the disease was assessed in points, which increased the total sum, indicative of its more severe manifestation. The results obtained were assessed by biostatistics and clinical epidemiological methods ${ }^{18}$. The constellation pattern of ATP caused by BHSA or other microorganisms was simulated by means of the successive Waald's method in Kulbak's modification $^{19}$.

\section{Results}

On admission to hospital and during 7 days of treatment, the clinical signs of ATP in children of both groups did not differ considerably. Thus, on admission of children from the $1^{\text {st }}$ group, the total sum of their signs was on average 42.4 points, and on the $7^{\text {th }}$ day of treatment 7.7 points. In patients of the $2^{\text {nd }}$ clinical group, during these periods of treatment, the signs of acute tonsillopharyngitis (ATP) were assessed as 44.5 and 7.6 points, respectively $(\mathrm{P}>0,05)$.

None of the clinical signs is able to indicate accurately the etiology of ATP and diagnostic value of different symptoms, as they do not have sensitivity and specificity more than $98 \%$. Therefore, combination of several symptoms into one clinical scale was considered to be reasonable. Centor system is an example of such combination, including assessment of the body temperature more than $38^{\circ} \mathrm{C}$, lack of cough, enlarged and painful cervical lymph nodes, tonsils' swelling with exudate ${ }^{14}$. Every sign is estimated as one point. Depending on the obtained total sum, a probable percentage of $\beta \mathrm{HSA}$ excretion in these patients is determined. In addition to the above parameters, MacIsaac system includes age ${ }^{13}$. Breeze system is more complex. It combines clinical, epidemiological and laboratory findings ${ }^{15}$.

The use of Maclsaac and Centor probabilistic-orientation clinical systems with the total sum less than 3 points was indicative of non-streptococcal nature of the disease. They were also characterized by high specificity (93.9\% and $90.9 \%$ respectively), but low sensitivity ( $12.5 \%$ and $20.0 \%$ respectively), with predicted value of positive and negative results on the level of $50.0 \%$. At the same time, the post-test probability of the event, that is, diagnosis of non-streptococcal acute tonsillopharyngitis, in case of a positive test increased with only $9.0 \%$. It should be noted that according to the given diagnostic systems, with assessment score of 3 and more points and the total sum more than 29 by Breeze system, sensitivity and specificity of the test to find streptococcal ATP was not higher than $60 \%$. The post-test probability of the event was increased by $9.0 \%$.

An insufficient diagnostic information value of clinical diagnostic systems to detect non-streptococcal tonsillopharyngitis compared with sATP, leads to inappropriate antibiotic therapy. This is explained by the small number of components included in these systems, and respectively, low rigidity caused by an alternative assessment of the results. Therefore, the use of constellation diagnostic system appears to be more promising in this regard. According to our data, it enables the diagnosis of non-streptococcal ATP or diseases caused by BHSA with an error of the first type $(\alpha)$ no more than $5.0 \%$. Table 1 presents a simplified variant of the clinical components of this system.

The evaluation with the suggested diagnostic constellation system consists of successive addition of diagnostic coefficients, and in case the threshold diagnostic value of $(+) 13$ points is achieved, nATP is diagnosed; in case of the total sum of (-)13 points, streptococcal acute tonsillopharyngitis is diagnosed.

Efficacy of the routine treatment ${ }^{1-3}$ of ATP in children from the groups of comparison did not differ significantly. On the $2^{\text {nd }}$ day of in-patient treatment, the signs of ATP decreased, on the $5^{\text {th }}$ day some symptoms were absent in $30 \%$ of children, and the other $70 \%$ had only mild manifestations.

The prospective 1-year observation of children who had ATP determined that every third child from the $1^{\text {st }}$ group and half of the representatives from the $2^{\text {nd }}$ group presented different complaints associated with vegetative-vascular dystonia (VVD) syndrome.

Kerdo index was used to assess the vegetative tonus. It was calculated by the formula VI=1-(DP/ $\mathrm{HR}) \times 100$, where DP - diastolic pressure in $\mathrm{mmHg}$, 
Table 1. Constellation-diagnostic table.

\begin{tabular}{|c|c|c|}
\hline Index & DC & IC \\
\hline Atopic dermatitis & -2.75 & 9.20 \\
\hline Close contact with ATP patients & 1.73 & 7.18 \\
\hline Passive smoking & -1.07 & 6.90 \\
\hline Low social family status & 1.04 & 4.92 \\
\hline Acute respiratory viral infections more than 4 per year & 0.93 & 5.41 \\
\hline ATP more than 5 per year & -1.61 & 5.14 \\
\hline Fever $37.5^{\circ} \mathrm{C}$ and less & 5.35 & 39.58 \\
\hline Fever more than $38.0^{\circ} \mathrm{C}$ & -1.56 & 8.60 \\
\hline Assessment of severity of symptoms on admission to hospital more than 45 points & -0.22 & 0.24 \\
\hline Cough & 1.77 & 10.43 \\
\hline Intoxication syndrome & -0.27 & 0.81 \\
\hline Coating on the tonsils more than 3 points & -0.83 & 4.83 \\
\hline Headache & -2.04 & 9.0 \\
\hline Enlargement of cervical lymph nodes & -0.65 & 3.78 \\
\hline Assessment by MacIsaac scale less than 3 & 3.12 & 9.97 \\
\hline Assessment by MacIsaac scale 5 points & -1.68 & 15.56 \\
\hline Assessment by Centor scale less than 3 points & 3.42 & 18.64 \\
\hline Assessment by Centor scale 3 and more & -0.88 & 4.39 \\
\hline Leukocytosis of the peripheral blood more than $10 \mathrm{~g} / \mathrm{L}$ & -1.76 & 12.94 \\
\hline Cold season of the year & 1.43 & 9.30 \\
\hline Assessment by Breeze scale more than 30 points & -1.52 & 11.28 \\
\hline
\end{tabular}

Notes: DC-diagnostic coefficient; IC - information coefficient.

HR - heart rate, beats per minute. A positive value (more than 10\%) is indicative of the sympathetic regulation prevalence of the vascular tonus. A negative one (less than 10\%) is indicative for the vegetative nervous system effect on the tonus. Negative results of Ruffier-Dickson's test to determine patients' fitness level, in case of dosed physical exercise in children with non-streptococcal ATP, were found in $2.6 \%$ of cases in the $1^{\text {st }}$ group and in $29.6 \%$ of cases from the $2^{\text {nd }}$ group $(p<0,05)$. It should be noted that between Kerdo index and negative results of Ruffier-Dickson's test there was a positive correlation: in children from the $1^{\text {st }}$ group, $\mathrm{r}=0.56(\mathrm{p}<0.05)$, and in patients from the $2^{\text {nd }}$ group $r=0.66(p<0.05)$. A relative risk of reduced capability of the heart in case of dosed physical exercise was considerably higher in children who experienced streptococcal ATP, compared with the representatives of $1^{\text {st }}$ group, and it was 15.8 (95\% CI 4.3-58.1).

Considering the results of the follow-up observation, with the aim to reduce the risk of undiagnosed streptococcal ATP, and in case of impossible microbiological examination with cultures, we have suggested the algorithm of a rational administration of antibiotics for its treatment (Figure 1).

The suggested algorithm for ATP treatment in children can be used successively or starting from any other level: either from the method of quick detection of BHSA antigen (in this case „Streptatest"), or by means of probabilistic-orientation clinical systems, or from the level of the constellation diagnostic system suggested by us. The clinical observations demonstrated that the risk of false-negative results decreases considerably and post-test probability of the event in case of a positive result of the test increases. Thus, assessment of clinical examination results, including III ${ }^{\text {rd }}$ level, finally decreases the error of I type to less than $5.0 \%$.

\section{Discussion}

Considering the inadequate diagnostic information value of certain ATP signs to determine the BHSA etiology of the disease, a number of orientation clinical and clinical-paraclinical scales have been introduced. Some authors believe that the combination of those signs enables to determine the probability of BHSA-etiology of the disease. Among these diagnostic systems, the scales introduced by Breeze (1977), Centor et al (1981), Komarof et al (1986), MacIsaac (2000) have received the utmost use. This rather incomplete list of diagnostic scales established on adding points that describe the expressiveness of clinical-paraclinical signs is itself indicative of their relative imperfection ${ }^{20-23}$. 


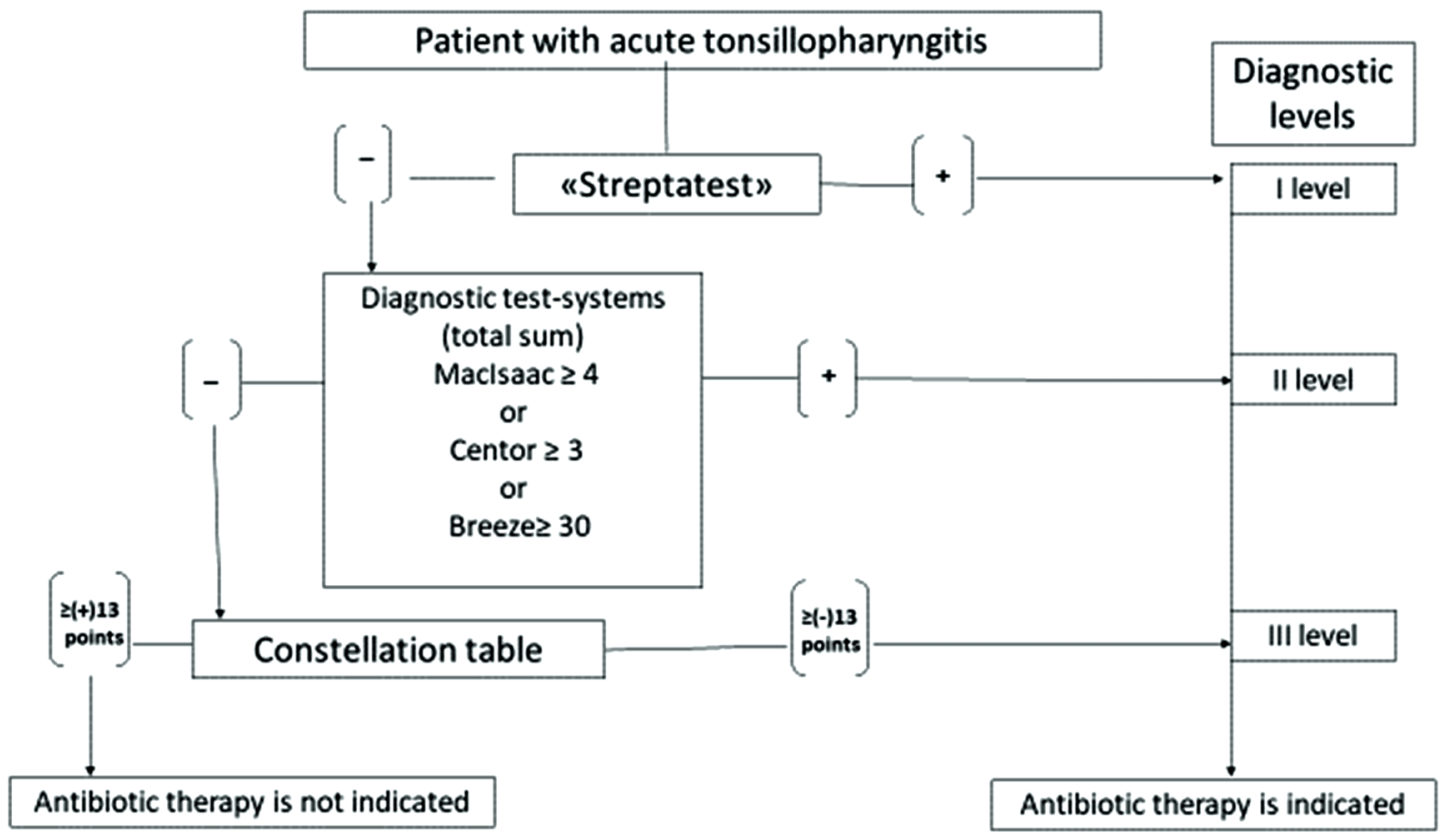

Figure 1. Algorithm of treatment of children with acute tonsillopharyngitis.

Our study found that the use of MacIsaac and Centor probabilistic-orientation clinical systems, with a high specificity but low sensibility and low predictable value of positive and negative results, was indicative of non-streptococcal etiology of the disease. In our opinion, the low value of the clinical diagnostic systems in order to detect non-streptococcal tonsillopharyngitis is explained by the small number of their constituents. A flexible multi-component diagnostic system is suggested in our study for a rational therapeutic approach.

\section{Conclusions}

Usually, probabilistic etiological diagnosis of acute tonsillopharyngitis in children, on the basis of discrete clinical symptoms, is ineffective. MacIsaac and Centor probabilistic-orientation clinical systems, with the total sum of less than 3, are indicative of non-streptococcal acute tonsillitis in children, with a high specificity, but low sensitivity. The total sum of 3 and more points does not enable to diagnose the disease caused by $\beta$-hemolytic streptococcus reliably. In children who experienced acute streptococcal tonsillopharyngitis, one year later, the risk of reduced cardiac performance during dosed physical exercise increased considerably. To reduce the risk of insufficient diagnosis of acute tonsillopharyngitis caused by $\beta$-hemolytic streptococcus when microbiological examination with cultures is not possible, multilevel algorithm of its treatment should be used.

\section{Compliance with Ethics Requirements:}

„The authors declare no conflict of interest regarding this article"

„The authors declare that all the procedures and experiments of this study respect the ethical standards in the Helsinki Declaration of 1975, as revised in 2008(5), as well as the national law. Informed consent was obtained from all the patients included in the study"

"No funding for this study"

\section{References}

1. Park SY, Gerber MA, Tanz RR, et al. Clinicians' management of children and adolescents with acute pharyngitis. Pediatrics 2006;117:1871-8.

2. Chiappini E, Regoli M, Bonsignori F, et al. Analysis of different recommendations from international guidelines for the management of acute pharyngitis in adults and children. Clin Ther 2011;33:48-58.

3. Shulman ST, Bisno AL, Clegg HW et al. Clinical practice guideline for the diagnosis and management of group A streptococcal pharyngitis: 2012 update by the Infectious Diseases Society of America. Clin Infect Dis 2012; 55:1279-82.

4. Regoli M, Chiappini E, Bonsignori F, et al. Update on the management of acute pharyngitis in children. Ital J Pediatr 2011;37:10.

1. Choby BA. Diagnosis and treatment of streptococcal pharyngitis. Am Fam Physician 2009;79(5):383-90.

6. Simel DL, Rennie D, Bossuyt PM. The STARD statement for reporting diagnostic accuracy studies: application to the history and physical examination. J Gen Intern Med 2008;23:768-74.

7. Boccazzi A, Garotta M, Pontari S. Streptococcal tonsillopharyngitis: clinical vs. microbiological diagnosis. Infez Med 2011;19:100-105. 
8. Rimoin AW, Hamza HS, Vince A, et al. Evaluation of the WHO clinical decision rule for streptococcal pharyngitis. Arch Dis Child 2005;90(10):1066-70.

9. Ruiz-Aragón J, Rodríguez López R, Molina Linde JM. Evaluation of rapid methods for detecting Streptococcus pyogenes. Systematic review and meta-analysis. An Pediatr (Barc) 2010;72(6):391-402.

10. Poliakov DP. Modern aspects of diagnostics of acute streptococcal tonsillopharyngitis in children. Issues of Modern Pediatrics 2013;12:46-51.

11. Gerber MA, Shulman ST. Rapid diagnosis of pharyngitis caused by group A streptococci. Clin Microbiol Rev 2004;17(3):571-80.

12. Bisno AL, Gerber MA, Gwaltney JM Jr, et al. Practice guidelines for the diagnosis and management of group A streptococcal pharyngitis. Infectious Diseases Society of America. Clin Infect Dis 2002;35(2):113-25.

13. McIsaac WJ, Kellner JD, Aufricht P, et al. Empirical validation of guidelines for the management of pharyngitis in children and adults. JAMA 2004;291:1587-95.

14. Centor RM, Witherspoon JM, Dalton HP et al. The diagnosis of strep throat in adults in the emergency room. Med Decis Making 1981;1:235-46.

15. Breese BB. A simple scorecard for the tentative diagnosis of streptococcal pharyngitis. Am J Dis Child 1977;131:514-517.

16. Clancy CM, Centor RM, Campbell MS, et al. Rational decision making based on history: adult sore throats. J Gen Intern Med 1988;3(3):213-7.

17. McIsaac WJ, Goel V, To T, Low DE. The validity of a sore throat score in family practice. CMAJ 2000;163(7):811-15.
18. Gubler EV. Computational approaches of the analysis and identification of pathological processes. Leningrad: Medicina;1978.294

19. Fletcher R, Fletcher S, Wagner E. Clinical Epidemiology: Fundamentals of Evidential Medicine. $3^{\text {rd }}$ edition. Moscow: Media Sphere; 2004.352

20. Komarof AL, Pass TM, Aronson MD, et al. The prediction of streptococcal pharyngitis in adults. J Gen Intern Med 1986;1:1-7.

21. Walsh BT, Bookheim WW, Johnson RC, Tompkins RK. Recognition of streptococcal pharyngitis in adults. Arch Intern Med 1975;135(11):1493-7.

22. Hoffman S. An algorithm for a selective use of throat swabs in the diagnosis of group: a streptococcal pharyngo-tonsillitis in general practice. Scand J Prim Health Care 1992;10(4):295-300.

23. Meland E, Digranes A, Skjaerven R. Assessment of clinical features predicting streptococcal pharyngitis. Scand J Infect Dis 1993;25(2):177-83.

24. Vranjes Z, Katić V, Vinter-Repalust N, et al. Acute infections of the upper respiratory tract-factors that contribute to diagnosis and antibiotic prescription decisions. Acta Med Croatica 2007;61(1):83-90.

25. Molochek SA. Modern approaches to the diagnosis and treatment of tonsillopharyngitis (a review of international guidelines). Actual Infectology 2016;3:9-16.

26. Polyakov DP. Modern aspects of the diagnosis of acute streptococcal tonsillopharyngitis in children. Questions of Modern Pediatrics 2013;12(3):46-51. 